\title{
Assessment of Professional and Personal Qualities in the Selection for Civil Service Positions: Evolution of Approaches
}

\author{
Andrei Luzakov \\ Kuban State University \\ Krasnodar, Russia \\ E-mail: latest@list.ru
}

\author{
Yulia Katkova \\ Kuban State University \\ Krasnodar, Russia \\ E-mail: emylife@ rambler.ru
}

\begin{abstract}
The article analyzes the evolution of official guidelines for assessing professional and personal qualities (competencies) when filling vacant posts in civil service in the Russian Federation over the past seven years. The current guidelines and innovations are analyzed. Problems that may arise in the process of implementation of recommendations in the practice of competitive selection are identified. The necessity of attracting third-party specialist consultants and the development of local models for assessing professionally important qualities that take into account the specifics of regions and different groups of posts, are substantiated. The possibilities of changing the list of evaluated qualities are discussed.
\end{abstract}

Keywords-civil service; selection of staff; personnel appraisal; assessment; personal qualities; professional qualities; competencies

\section{INTRODUCTION}

In recent years, the upper echelons of state power of the Russian Federation have become aware of the fact that the selection of applicants for the civil service should be based on best Russian and international practices that take into account scientific achievements in HR-management. This led to the rapid development of approaches and methods that were officially recommended and used in this area. The main tool designed to ensure equality in the filling of vacant civil service posts and the formation of qualified personnel is the competitive selection procedure [1]. One of the threats to the successful implementation of modern methods of selection and assessment is the peculiarities of the Russian mentality and the traditions of appointing senior personnel. According to a number of authors, the famous psychologist A.V. Yurevich in particular, the socio-psychological mechanisms of personnel policy is based on the priority role of personal devotion and informal relations. This leads to a decrease in the intellectual potential and moral qualities of officials and the growth of the negative moods among the population [2]. At the same time, the actions of the federal authorities in the sphere of control over the behavior of officials and the reduction in the number of people who inspire optimism have recently been noticed. We will consider how, over the course of just a few years, the ideas about the quantity and content of qualities to be evaluated and about the methods of evaluation have progressively changed. We will also analyze the current guidelines and innovations and identify problems that may arise in the process of their implementation in practice, as well as the prospects for changes in the list of qualities that should be evaluated.

\section{The CONTENT AND WAY OF Evaluation:}

EVOLUTION OF SUBMISSIONS AND METHODOLOGICAL RECOMMENDATIONS

The tasks and criteria for evaluating candidates during selection for vacant positions and the tasks of evaluating existing employees differ, although in both cases a fairly similar list of evaluated characteristics should be applied. The selection of competencies for assessment should be preceded by a thorough analysis of the work performed by employees of a certain group of posts. Therefore, the assessment model usually "moves" from studying the existing employees to the formation of evaluation criteria for applicants, and not vice versa. The number and content of competencies to be assessed usually varies for different categories of personnel and depends on the profession and the field of activity of the organization. With regard to the civil service, the question of what and how should be assessed has been posed and resolved in different ways over the past seven years, which can be tracked through official documents. In a comprehensive assessment of a working employee, it is advisable to distinguish three aspects of assessment: assessment of qualifications, assessment of efficiency and effectiveness (by key performance indicators), and assessment of professional qualities (competencies). This principle was used in the "Methodological Toolkit for the Implementation of a Comprehensive Assessment System for the Professional Performance of Civil Servants (including Public Assessment)" which was developed by the Ministry of Labor of the Russian Federation in 2013. Qualification assessment here was interpreted as compliance with the requirements for education, seniority in the civil service or work experience in a specialty, and as an assessment of the necessary professional knowledge and skills (this implied the use of knowledge tests). We will leave aside the problems of the formal assessment of qualifications and assess the effectiveness / efficiency of the employee and focus our attention on the problems of assessing professional qualities, 
because it is they that most of all cause disagreement among theorists and difficulties among practitioners.

Attached to the "Methodological Instrumentation ...," the reference book of professional qualities of civil officers contained 19 qualities, divided into three groups: general professional qualities, applied professional qualities, and managerial professional qualities. General professional qualities included qualities that every civil officer should possess, regardless of the position being replaced. These include: focus on the result; strengthening the authority of civil servants; interpersonal understanding and communication style. Applied professional qualities included: collection and analysis of information; high-quality preparation of documents; orientation to ensure the protection of the legitimate interests of citizens; etc. (eight in all). They are necessary for the effective performance, depending on the functional characteristics of the position. The managerial professional qualities included: planning of activities and resources; setting goals and organizing activities; control and assessment of performance; motivation and development of subordinates; management decisions; strategic vision; change management; public speaking and external communications.

It was proposed to form models of professional qualities for each post (group of posts) in the personnel service of a state body with the involvement of experts. It was recommended that the model contain 10 professional qualities, including 3 general professional qualities and 7 professional qualities related to applied and (or) managerial professional qualities.

The list of qualities for evaluating activity in the future only partially influenced the formation of the list of qualities for evaluating applicants during the selection. In this list, one can trace some meaningful analogies with those qualities that were previously proposed for a comprehensive assessment of the performance of employees in the 2013 Methodological Instrumentation in the "Methodological toolkit for hiring planning and organizing the selection of personnel for filling the posts of civil service. Version 2.0." It was developed by the Ministry of Labor and Social Protection of the Russian Federation in 2015. In the section devoted to the assessment methodology in the selection of candidates, the concept of "professional qualities" is used (the concept of "competencies" is not used), which are revealed through behavioral indicators. The professional qualities to be assessed included: Systemic thinking; Foresight; Responsibility for the result; Initiative; Effective communication; Professionalism (understood as a high level of professional knowledge); The pursuit of quality; Effective organization of work; Leadership; Creativity; Change management; Information gathering; Information analysis; People management; Flexibility, and Mentoring. Note that this list is quite long, and in our opinion, too long, because on the basis of international experience, HR-specialists recommend limiting qualities for evaluation to five-to-nine. In this list, one can trace some meaningful analogies with those qualities that were previously proposed for a comprehensive assessment of the performance of employees in the 2013 Methodological Instrumentation. But there were a lot of terminological and substantive differences in these documents, which fact impeded the work of HR-specialists. It was proposed to evaluate the intensity of professional qualities in points on a four-level scale. where ' 3 ' means that the quality is pronounced, ' 2 ' means that it is present (expressed), ' 1 'means that the quality is ill-defined, and ' 0 ' means that the quality is not expressed at all.

On October 15, 2016 there appeared Decree of the Government of the Russian Federation No. 1050 entitled "On the organization of project activities in the Government of the Russian Federation." It contained changes in the terminology. Now the term "competencies," which was not previously used in the mentioned methodological developments is recommended. Most likely, this is due to the new list of developers. The functions of the project management competencies Center began to be performed by the Scientific and Educational Center for Project Management of the Russian Academy of National Economy and Public Administration (RANEPA). The Ministry of Labor, together with the Center for Project Management Competencies, proposed "Guidelines for the organization and conduct of qualifications assessment of civil servants in the field of project activities." Assessment focuses on three elements, which are now called: qualifications, personal and managerial competencies, and applied competencies. The terms used in this document are in many respects consistent with the terms used in the "Methodological tools for establishing qualification requirements for filling the posts of the civil service (Version 3.2)".

Qualification assessment in these guidelines is interpreted as the process of determining competencies necessary for the implementation of project activities. The qualification assessment procedure for civil servants participating in project activities is carried out in the form of an exam taken by an expert commission approved by the Project Management Competencies Center. Personal and managerial competencies are understood as individual personality traits, manifested in behavior and reflecting life values, knowledge and skills that are necessary for the effective implementation of project activities. Applied competencies are characteristics manifested in a person's behavior that demonstrate knowledge and skills necessary for the effective implementation of project activities in accordance with the role played in the project.

Personal and managerial competencies for project activities are presented as follows: Leadership, Strategic Thinking, Management Decision Making, Personal Effectiveness, Teamwork, Flexibility and Willingness to change. Each of the six competencies is represented by a set of behavioral indicators. For example, Strategic Thinking is the ability to see the situation holistically (integrally), to predict the development of events, the ability to identify and justify strategic priorities, and to see risks and new opportunities.

It was recommended that an assessment of the compliance of the employees with the requirements for personal and managerial competencies of participants in project activities be carried out through self-assessment in 
Competence is defined in the document as a complex of accordance with the list of competencies whose intensity is measured in points on a 4-level scale: the expert level "I can teach", the qualified level "I apply", the basic level "I understand", the zero level "I do not apply."

The following skills were identified as applied competencies: organization of the project, project benefits management, project content management, project finance management, etc. (twelve in all). Assessment of applied competencies was to be carried out through testing knowledge.

This document concerned only the scope of project activities, but it formulated six professional and personal qualities, which then became the basis for subsequent developments regarding selection for all other activities.

\section{CURRENT RECOMMENDATIONS: INNOVATION}

An important milestone was the "Unified methodology of holding contests for filling vacant posts in the state civil service and inclusion in the personnel reserve of public bodies" [1]. It was approved by Decree of the Government of Russia dated March 31, 2018, No. 397. Again, there is a refusal to use the concept of "competencies"; it is about "professional and personal qualities" that need to be assessed. The ambiguous attitude of different specialists to the term "competencies" in Russia is manifested not only in the discussed sphere of norm-setting, but also in the field of education. Federal state educational standards in the Russian Federation that define what students need to be taught are formulated in terms of competencies, while professional standards developed in recent years do not use this concept, but use the concepts of labor functions, knowledge, and skills.

In the "Unified methodology ..." six professional and personal qualities for evaluation are named. In accordance with the wording, they coincide with the list that was previously presented as "personal and managerial competencies" in the above-mentioned "Guidelines for the organization and conduct of qualifications assessment of civil servants in the field of project activities" (2016). They are "Strategic Thinking", "Team Interaction", "Personal Efficiency", "Flexibility and Readiness for Change" for all candidates, plus "Leadership" and "Management Decision Making" for candidates applying to fill civil service posts in the categories "managers" of all job groups and "specialists" of the highest, main and leading job groups.

To assess these qualities, it is proposed to use the following methods: individual interviews, questionnaires, conducting group discussions, writing essays and other written works, or testing on issues related to the performance of duties in a vacant position.

The "Methodological Instrument for the Formation of the Personnel of the Civil Service of the Russian Federation (Version 3.1)" [3] was developed that same year in full accord with the conceptual apparatus of the "Unified methodology ..." This document concretizes concepts and details assessment methods. The above terminological contradiction is partially removed here: professional and personal qualities in brackets are called competencies. professional and personal qualities manifested in the behavior of a civil servant, indicating the presence of knowledge, skills, and experience of professional activity necessary for effective and efficient performance of official duties [3]

Each quality (competence) is evaluated through three to seven behavioral indicators. The four-level rating scale (3 quality pronounced, 2 - pronounced, 1 - poorly expressed, 0 not expressed at all) is supplemented by the position "no data". The rules for evaluating a candidate according to behavioral indicators related to one or another quality are stated.

Some concepts and methodological requirements that are obvious to specialists in personnel appraisal and psychodiagnostics in large commercial organizations, have officially appeared as valuable innovations in official documents over the past several years. Current recommendations use the concept of "ability test" and gives recommendations on the selection of ready-made testing methods. Previously, the concept of "test" in documents for the civil service was used mainly as a synonym for the knowledge test. The following recommendation should be recognized as an important step: when interacting with a supplier of testing methods, ask them to provide data on the reliability and validity of the test.

It is emphasized that ability tests are not developed for a specific post, but for a group of posts. The idea of normative groups is introduced. In psycho-diagnostics it is well known that transferring test norms from one group to another delivers incorrect assessment results. In the document under analysis it is noted that ability tests should have several normative groups. Moreover, it is desirable to have a large number of groups (sampling standardization) created for various positions, regions, and even for the time of testing. When interacting with a supplier, it is important to ask for a list of their sampling standardization for different tests with the description of the sample details [3].

It has been taken into account that requirements for employees change over time. Therefore, constant research is required in order to create new versions of tests and to update standards, norms of tests. It is not recommended to use tests that are freely available (for example, on the Internet) without the permission of the copyright holder, as there is a risk of violating intellectual property laws. It is recommended to ask the supplier for documents confirming their rights to this technique. It is necessary to add that at present, Russian developers of tests most often use the certificate of the Federal Intellectual Property Service (Rospatent) to register the test as a computer program, or, if a foreign company owns the test rights, enter into a partnership agreement with the copyright holder.

\section{PROBLEMS}

These innovations that are progressive for the civil service raise a number of problems that will have to be addressed in the coming years at the level of the subjects of the federation and throughout the country. 
It is necessary to improve the qualifications of employees of personnel services of state bodies, as well as of their structural divisions and / or project teams in the field that is new for them, viz. in personnel appraisal and psychometrics. These functions in their modern sense were not previously included in the duties of this category of personnel. For example, such employees cannot, as a rule, conduct a behavioral interview (competency interview) without special training. Our experience of working with HR-specialists shows that using only the recommendations from the "Methodological Toolkit for the Formation of the Staff ...", they find it difficult to develop a rating scale for qualities that can be assessed using interviews, group discussions, and written works of applicants. The interview guidelines provide examples of questions aimed at identifying a particular competence, but it is not explained clearly and in detail, what answers are to be evaluated and in what way. Additional difficulties for personnel officers are created by the inconsistency in the document of some particular assessment criteria (skills identified during a specific task) with the final criteria - professional and personal qualities. It is clear that without a consulting support the use of recommended methodological tools for HR-specialists will not be easy.

The Ministry of Labor proposes to introduce assessment center procedures in the civil service. On the one hand, this is a positive phenomenon, as assessment centers have long been used in different countries and have proved themselves successful. On the other hand, a widespread adoption of assessment technologies in the civil service system will create a number of problems. Professional requirements for these procedures are very high [4], and many aspects of this technology are still poorly studied [5]. Due to additional organizational and financial costs, the use of an assessment center is recommended only when selecting applicants for civil service positions in the "leaders" category of the highest, main and leading groups of civil service posts, as well as for some other posts.

A serious problem in conducting assessment in an assessment center is the need to attract specially trained appraisers (evaluators). Although the "Unified Methodology ..." obliges us to introduce independent experts and personnel appraisal experts into the tender committee, such specialists are still few in number and will not be able to satisfy the growing demand for their services. Moreover, the payment system for such services has not yet been thought over everywhere. Attracting consulting organizations for these purposes has also not yet been worked out, at least for the regions.

The behavioral indicators recommended by the "Unified Methodology..." are very different from each other in how accurately they can be assessed during the proposed procedures, especially if the candidate was not previously known to the members of the competition committee. Some indicators may manifest themselves in labor behavior, but it is problematic to assess their intensity in the candidate's situational behavior during brief assessment procedures. For example, the indicator "Establishes and maintains long-term partnerships with other people inside and outside the organization and expands the circle of contacts".

Behavioral manifestations observed in interviews are poorly protected from the effects of social desirability. The candidates' skillful demonstration of similarity to the expert's position, their own abilities, skills and achievements contribute to the formation of a positive impression. The ability to self-monitoring is manifested in the rapid determination of signs of desired behavior in a significant situation and in the modification of their behavior [6]. It is necessary to render assistance to HR-specialists to prepare them for the recognition of such tactics.

\section{PROSPECTS FOR CHANGING THE QUALITY LIST WHICH SHOULD BE EVALUATED}

If we digress from the discussion of a specific methodology for assessing applicants for civil service, we should mention a more global problem - ongoing disputes over the classification of competencies. A study of scientific papers on issues of managerial activity shows the lack of a universally recognized set of managerial competencies. The priority of choosing one or another competence depends on the socio-economic conditions, the field of activity, the popularity of a particular managerial concept, and the experience of leading organizations. Over the past decades, various authors have proposed many different models of competencies. A critical analysis of such models begins with a logical question, why there are five, seven, or ten competencies and why a certain behavioral indicator is related to that and not another generalized competence. Modern organizational and production environment is a less rigid system of functions and roles and is becoming more and more obscure. In the new models of managerial competencies, it is not so much the tasks and functions of the subject of management or the desired methods of managerial actions that are fixed as characteristics allowing the subject to independently find guidelines [7]. In the content of competencies, emphasis is shifted from socially defined constructs to a subject who is actively shaping the meanings of their own activity.

In the model of professional and personal qualities (competencies) discussed here for the selection of civil servants, qualities related to the personality maturity of the applicant for the position are not sufficiently represented. This is especially important for managerial positions. While improving as a professional, a person develops as a personality. But the interconnection between professional maturity, work experience and personal maturity is often ambiguous and not linear. Personal maturity is more difficult to explore through external manifestations. But even at the level of everyday consciousness it was noticed that personally mature leaders have a more pronounced influence on their subordinates. Attempts to reveal the structure of the construct "personal maturity of the leader" are presented in the work of B.A. Yas'ko, A.A. Luzakov, M.G. Ostroushko [8]. Various authors mention the following components in their works: ability to build constructive relations; an adequate self image; self-government and self-development; productive activity and creativity; responsible autonomy; 
[3] Ministry of Labor and Social Protection of the Russian Federation (2018). Methodological tools for the formation of the personnel in the state civil service of the Russian Federation. Version 3.1. Retrieved from: https://rosmintrud.ru/ministry/programms/gossluzhba/16/2.

hierarchy of motives and realistic claims.

The level of maturity of a person as a subject of cognition can be evidenced by the methods of categorizing the people inherent in this person, as well as by personality constructs. A special area of categorization for any leader is the designation of abilities and qualities that function in his mind, with the help of which he distinguishes between successful and unsuccessful managers, places them into certain classes, and compares them with himself [8] [9]. Studying such subjective coordinate systems and subsequent counseling can help the process of self-improvement of the executives and smooth out (moderate) the problems of inconsistency of the employee's own construct system with the list of competencies being assessed, which is imposed "from above".

\section{CONCLUSION}

The history of the appearance and evolution of the content of official documents and methodological recommendations regarding competitive selection for the posts in the state civil service, as well as the assessment of employees' professional activities has been carried out in the research. It has been shown that the Government of the Russian Federation gave an impetus to the progressive development of personnel selection and to assessment technologies in the civil service system which had previously been quite conservative with regard to these issues and noticeably lagged behind the best practices of HR management. However, the introduction of new technologies is likely to face difficulties. Among the existing problems and upcoming areas of work, we will name the following. Insufficient qualifications of staff of HR-departments of state bodies in the field of modern technologies for assessing personnel are often the reason for their lack of understanding of new methodological recommendations; they limit the possibility of implementing these recommendations in practice. The need to attract a large number of third-party specialist consultants will require additional financial and organizational resources. It is necessary to develop local models for assessing professional and personal qualities taking into account the specifics of the regions and the functionality of different groups of positions. It is necessary to organize studies on an ongoing basis to develop new versions of tests and to update and localize test standards. The possibility of justified changes and the localization of the list of qualities (competencies) that should be evaluated must be taken into account. Future changes may relate to the number of competencies and their contents.

\section{REFERENCES}

[1] SZRF (No. 16, Art. 2359 (part II). (2018). Unified methodology for holding contests for filling vacant positions in the state civil service and inclusion into the personnel reserve of state bodies [Text]: Decree of the Government of the Russian Federation of March 31, 2018. No. 397

[2] Yurevich, A. V. (2017). Socio-psychological mechanisms of personnel policy. Psychological journal, 38 (6), 88-97. 